\title{
Prospective Science Teacher TPACK Skills in Preparing the Lesson Plans
}

\author{
Dais Shopie Azizah $^{* 1)}$, Dea Anjani Putri ${ }^{2)}$, Diah Mulhayatiah ${ }^{3)}$ \\ 1,2,3) Physics Education, Faculty of Tarbiyah and Teaching Training, \\ UIN Sunan Gunung Djati Bandung \\ e-mail: ${ }^{* 1)}$ mshofiel.azizah21@ gmail.com \\ deaanjaniputri12@gmail.com \\ diahmyusuf@gmail.com
}

\begin{abstract}
Prospective teacher education is faced with the issue of integrating technological pedagogical and content knowledge (TPACK). Prospective teachers are expected to become teachers who are skilled at teaching effectively, mastering content, and are able to utilize technology in the learning process. The ability of TPACK for prospective science teacher can be seen from the preparation of a lesson plan, because there are elements of pedagogy, content, and technology in it, and it is seen from the suitability of the lesson plans with the implementation of learning by teachers in the classroom. Moreover, in implementing science learning, students must apply a scientific attitude to support learning so that students not only understand the theory but also master real concepts. The purpose of this study was to analyze the skills of prospective science teachers to apply TPACK in preparing lesson plans so that the weaknesses and strengths could be identified. The research method used is library research, by examining several sources related to the skills of prospective science teachers in implementing TPACK through the preparation of the lesson plan. The results of the research showed that some prospective science teachers still lacked skills in using integrated technology in the preparation of lesson plans, and the implementation of learning was not optimal so that it became a big challenge that science teachers had to face in the industrial revolution 4.0. Implementing TPACK in the preparation of the lesson plan can improve the quality of learning. The advantages produced can be seen from the effectiveness of the learning process provided through the use of technology in learning.
\end{abstract}

Keywords: prospective science teacher, lesson plan, TPACK. 


\title{
Keterampilan TPACK Calon Guru IPA dalam Menyusun Rencana Pelaksanaan Pembelajaran
}

\author{
Dais Shopie Azizah ${ }^{* 1)}$, Dea Anjani Putri ${ }^{2)}$, Diah Mulhayatiah ${ }^{3)}$ \\ 1,2,3) Pendidikan Fisika, Fakultas Tarbiyah dan Keguruan, UIN \\ Sunan Gunung Djati Bandung
}

\begin{abstract}
Abstrak
Pendidikan calon guru dihadapkan pada masa dengan isu integrasi pengetahuan konten, pedagogi, dan teknologi atau dikenal technological pedagogical and content knowladge (TPACK). Calon guru diharapkan menjadi guru yang terampil mengajar dengan efektif, menguasai konten, dan mampu memanfaatkan teknologi dalam proses pembelajaran. Kemampuan TPACK calon guru IPA dapat dilihat dari penyusunan rencana pelaksanaan pembelajaan (RPP), karena didalamnya terdapat unsur pedagogik, konten dan teknologi, serta ditinjau dari kesesuaian antara RPP dengan pelaksanaan pembelajaran oleh guru di dalam kelas. Terlebih lagi dalam pelaksanaannya pembelajaran IPA harus menerapkan sikap ilmiah untuk menunjang pembelajaran agar siswa tidak hanya memahami teori, namun juga menguasai konsep secara real. Tujuan kajian ini adalah menganalisis keterampilan calon guru IPA menerapkan TPACK dalam menyusun RPP, sehingga dapat diketahui kekurangan dan kelebihannya. Metode penelitian yang digunakan adalah library research, dengan mengkaji beberapa sumber terkait keterampilan calon guru IPA dalam menerapkan TPACK melalui penyusunan RPP. Hasil kajian diperoleh masih kurangnya kecakapan sebagian calon guru IPA dalam menggunakan teknologi secara terintegrasi dalam penyusuan RPP, serta belum optimalnya pelaksanaan pembelajaran, sehingga menjadi satu tantangan besar yang harus dihadapi guru IPA dalam revolusi industri 4.0. Dengan menerapkan TPACK dalam penyusunan RPP, dapat meningkatkan kualitas pembelajaran. Kelebihan yang dihasilkan dapat dilihat dari efektif tidaknya proses pembelajaran yang dilakukan melalui penggunaan teknologi dalam pembelajaran.
\end{abstract}

Kata kunci: calon guru IPA, RPP, TPACK.

\section{Pendahuluan}

Menjadi pendidik di abad ke 21 memiliki banyak tantangan yang harus dilewati, karena di era globalisasi yang semakin maju pesat ini teknologi semakin canggih. Untuk mencapai tujuan pendidikan nasional Republik Indonesia yaitu dengan mencerdaskan kehidupan bangsa, maka dalam sistem pendidikan kita harus terus berbenah. Pembenahan yang mendasar dalam pendidikan adalah terkait kualitas dan kompetensi guru dan calon guru Indonesia. Calon guru harus mencermati bagaimana kualitasnya untuk menjadi guru, bagaimana menyadari posisi mereka dalam era revolusi industri saat ini (Arbiyanto et al., 2018).

Tuntutan pembelajaran abad 21 yaitu integrasi teknologi sebagai media pembelajaran untuk mengembangkan suatu keterampilan belajar, sehingga calon guru harus memiliki keterampilan dalam bidang teknologi dalam meningkatkan hasil pembelajaran dan memfasilitasi proses serta tersedianya perangkat pembelajaran seperti RPP (Yusuf et al., 2015). Karena masih banyak calon guru yang tidak membuat task, rubrik, sebagai perangkat pembelajaran (Wulan, 2016).

Untuk menunjang upaya tersebut, terdapat suatu jenis pengetahuan baru, yaitu TPACK (Technological Pedagogic and Content Knowledge). TPACK dapat dijadikan sebagai kerangka kerja untuk mendesain kurikulum pendidikan guru yang lebih sesuai dengan era dan tuntutan pembelajaran abad 21 (Rahmadi, 2019). TPACK merupakan pengembangan dari framework yang dikenalkan oleh Shulman (1986) yaitu PCK (Pedagogical Content Knowledge). Didalam TPACK terdapat 3 jenis perpaduan pengetahuan yaitu:

1. Technological Knowledge (TK) adalah pengetahuan tentang berbagai jenis 
teknologi sebagai alat, proses, maupun sumber.

2. Pedagogical Knowledge (PK), pengetahuan tentang teori dan praktek.

3. Content Knowledge (CK), pengetahuan konten atau materi pembelajaran.

Hasil perpaduan 3 pengetahuan dasar tersebut, menghasilkan 3 pengetahuan baru meliputi:

1. Pedagogical Content Knowledge (PCK), pengetahuan pedagogik yang berhubungan dengan konten khusus, pengembangan perangkat pembelajaran yang utuh (RPP, media pembelajaran, bahan ajar, dan perangkat evaluasi).

2. Technological Content Knowledge (TCK), pengetahuan tentang timbal balik antara teknologi dengan konten.

3. Technological Pedagogical Knowledge (TPK), yaitu pengetahuan tentang berbagai teknologi yang dapat digunakan sebagai fasilitas pembelajaran (Rahmadi, 2019).

Keenam pengetahuan tersebut harus dikuasai oleh calon guru IPA termasuk guru fisika, biologi, dan kimia masa kini dan masa depan yang akan mengajar dalam lingkungan belajar yang dipenuhi dengan berbagai macam instrumen teknologi. Begitu juga dalam penyusunan RPP sebagai acuan guru dalam mengajar selama satu semester ke depan. Penguasaan konsep TPACK dapat dilihat berdasarkan keberhasilan calon guru IPA dalam menguasai pembelajaran secara aktif di kelas, salah satunya dilihat dari kemampuan dalam menyusun RPP yang digunakan sebagai pedoman pelaksanaan pembelajaran. Penyusunan RPP menggunakan TPACK bukan hanya memenuhi kriteria TPACK dengan menyisipkan penggunaan teknologi dalam pembelajaran saja (Sholihah et al., 2016).

Pelaksanaan pembelajaran IPA harus menerapkan sikap ilmiah untuk menunjang pembelajaran, agar peserta didik tidak hanya memahami teori, namun juga menguasai konsep secara real. Oleh sebab itu, salah satu hal utama yang harus diperhatikan adalah penyusunan RPP, dimana RPP merupakan langkah untuk menyiapkan pembelajaran satu semester ke depan. Dalam menyusun RPP menggunakan TPACK itu terletak pada analisis tujuan dan aktivitas belajar, yang mana untuk mencapai tujuan pembelajaran tersebut, perlu dipilih teknologi yang sesuai (Harris et al., 2012).

Kemampuan TPACK guru IPA dapat dilihat dari penyusunan rencana pembelajaan (RPP), karena didalamnya terdapat unsur pedagogik, konten, dan teknologi. Selain itu dapat juga ditinjau dari kesesuaian antara RPP dengan pelaksanaan pembelajaran oleh guru di dalam kelas (Innaha, 2018). Penerapan TPACK bagi guru telah diteliti oleh Koh et al. (2014) yang hasilnya menjelaskan kemampuan seorang guru dalam memadukan teknologi, pedagogik, dan pengetahuan isi materi sangat mempengaruhi cara guru dalam mengajar di kelas. Berkaitan juga dengan cara memilih metode, media, dan perangkat pembelajaran seperti RPP (Reski \& Sari, 2020).

Menurut hasil kajian (Sholihah et al., 2016) bahwa pembuatan RPP yang mengandung TPACK, masih terbilang rendah dan banyak calon guru fisika yang belum menerapkannya sebagai bekal atau persiapan menjadi guru profesional. Padahal kemampuan TPACK calon guru IPA atau guru fisika dalam menyurun RPP dapat meningkatkan kualitas pembelajaran. Karena itulah perlu dilakukan kajian mengenai analisis kemampuan TPACK calon guru IPA dalam menyusun rencana pelaksanaan pembelajaran (RPP).

\section{Metode Penelitian}

Metode yang digunakan adalah metode penelitian kepustakaan (library research) dengan menggunakan literatur atau sumber kepustakaan. Studi kepustakaan adalah teknik pengumpulan data dengan mengadakan studi penelaahan terhadap buku-buku, literaturliteratur, catatan-catatan, laporan-laporan, yang ada hubungannya dengan topik pembahasan (Nazir, 2003).

Teknik pengumpulan data yaitu dengan mengkaji pustaka terbaru terbitan 5 tahun terakhir terkait penggunaan TPCAK, selain itu juga terdapat beberapa sumber dari terbitan lama. Penelitian pustaka memanfaatkan jurnal, bahan-bahan dan informasi yang relevan untuk dikumpulkan, dibaca dan dikaji, serta dicatat sebagai pedoman ataupun sumber 
referensi. Metode studi pustaka ini dapat dijadikan sebagai data dan sumber data mengenai topik masalah. Library Research ini diterapkan untuk memberikan gambaran kepada pembaca tentang topik yang sedang diteliti (Rondiyah, 2017).

Teknik analisis yang digunakan adalah analisis deskriptif kritis yang lebih menekankan pada kekuatan analisis sumbersumber, maupun data-data yang ada dengan mengandalkan teori dan konsep yang ada, untuk diinterpretasikan berdasarkan tulisan yang mengarah kepada pembahasan. Sumbersumber tersebut didapat dari berbagai karya ahli yang berkompeten sesuai dengan pembahasan.

\section{Hasil dan Pembahasan}

Seperti yang telah dibahas pada pendahuluan bahwa penulisan artikel ini bertujuan untuk mengetahui keterampilan TPACK calon guru IPA dalam proses penyusunan RPP, sehingga yang perlu di pahami terlebih dahulu adalah apa itu TPACK dan mengapa calon guru IPA wajib memiliki keterampilan tersebut. Kemudian bagaimanakah keterampilan TPACK calon guru IPA dalam penyusunan RPP. Rencana pelaksanaan pembelajaran pada hakekatnya merupakan perencanaan jangka pendek untuk memproyeksikan atau memperkirakan apa yang akan dilakukan dalam pembelajaran. Hasil kajian diperoleh analisis TPCAK terkait penyusunan RPP sebagaimana ditunjukkan pada Tabel 1.

Rencana perangkat pembelajatran (RPP) merupakan upaya untuk memperkirakan tindakan yang akan dilakukan dalam kegiatan pembelajaran. RPP perlu dikembangkan untuk mengkordinasikan komponen pembelajaran yaitu: kompetensi dasar, materi standar, indikator hasil belajar, dan penilaian. Kompetensi dasar berfungsi mengembangkan potensi peserta didik; materi standar berfungsi memberi makna terhadap kompetensi dasar; indikator hasil belajar berfungsi menunjukkan keberhasilan pem-bentukan kompetensi siswa.

Sedangkan penilaian berfungsi mengukur pembentukan kompetensi, dan menentukan tindakan yang harus dilakukan apabila kompetensi dasar belum terbentuk atau belum tercapai (Mulyasa, 2007). Sebagai acuan pada penggunaan TPACK dalam pembelajaran masa kini adalah semakin pesatnya perkembangan teknologi diabad 21 ini. Oleh karena itu, TPACK ini menjadi kerangka kerja atau framework yang seharusnya dapat digunakan untuk menganalisis pengetahuan baru terkait integrasi teknologi dalam proses pembelajaran (Rahmadi, 2019).

Untuk mengintegrasikan CK, PK, dan PCK menjadi satu kesatuan yang utuh dan dapat menghasilkan proses pembelajaran yang efisien, efektif, dan menarik. Sudah seharusnya calon guru sebagai pendidik dimasa kini dan masa depan tentunya lebih meningkatkan keterampilannya di era Masyarakat Ekonomi Asean (MEA) ini, sehingga nantinya dapat bersaing dan lebih berkembang untuk menjadi pendidik yang profesional (Sintawati \& Indriani, 2019). Salah satu perangkat pembelajaran yang harus dilengkapi dan penting dalam proses pembelajaran selama satu semester ke depan yaitu RPP yang harus direncanakan secara matang. Diharapkan RPP yang disusun dan dilaksanakan dengan menggunakan TPACK dapat lebih meningkatkan hasil belajar siswa. Penyampaian materi belajar kepada siswa, tidak terlepas dari metode, media, dan perangkat pembelajaran yang digunakan (Fakhruddin et al., 2007). Oleh karena itu, kemampuan calon guru dalam mengembangkan bahan ajar dan perangkat pembelajaran diperlukan untuk menghasilkan pembelajaran yang menarik, berbasis digital, dan bermuatan landasan ilmu pendidikan.

Penelitian yang dilakukan oleh Eka Ariyati (2018) menyatakan bahwa keterampilan PCK calon guru biologi dalam penyusunan RPP termasuk kategori baik yaitu $(71,06 \%)$ artinya sudah banyak calon guru yang menerapkan TPACK dalam proses penyusunan RPP, sedangkan untuk guru fisika mendapati hasil penerapan TPACk masih rendah (Sholihah et al. 2016). Dengan demikian dapat dikatakan bahwa penerapan TPACK dalam penyusunan RPP bagi guru IPA secara keseluruhan belum terlaksana secara optimal. Proses penyusunan RPP menggunakan TPACK bukan hanya dalam proses pembuatan saja, tapi juga dalam proses pembelajaran berlangsung menggunakan teknologi didalamnya. 
Tabel 1. Artikel terkait penerapan TPACK dalam perangkat pembelajaran

\begin{tabular}{cll}
\hline No & \multicolumn{1}{c}{ Artikel Terkait } & \multicolumn{1}{c}{ Uraian } \\
\hline 1 & Chusni, Winda Setya, Agustina, \& & Hasil kajian terkait kemampuan menyusun RPP yang \\
Malik. (2017). Peningkatan & masih menunjukan banyak kesalahan. Diantaranya \\
Kemampuan Menyusun Rencana & dalam aspek menuliskan identitas RPP yang tidak \\
Pelaksanaan Pembelajaran (RPP) & lengkap, dalam merumuskan tujuan pembelajaran yang \\
Berbasis Saintifik bagi Calon Guru & tidak sesuai dengan indikator, dalam pemilihan media \\
Fisika, 125-143. & yang tidak sesuai dengan materi, dan dalam menyusun \\
& skenario belum berbasis saintifik. \\
Supriyadi, Bahri, \& Waremra. & Peningkatan kemampuan TPACK yang paling \\
(2018). Kemampuan Technological & signifikan adalah pada kemampuan pedagogik dan \\
Pedagogical Content Knowladge & kemampuan pengetahuan. Terkait dua kemampuan ini, \\
(TPACK) Mahasiswa pada & mahasiswa sudah mampu memilih model pembelajaran \\
Matakuliah Strategi Belajar & sesuai materi yang diajarkan. Sedangkan pada \\
Mengajar Fisika, 1-9. & kemampuan teknologi masih mendapatkan hasil \\
& penilaian yang rendah. Hal ini terkait faktor kebiasaan \\
& serta kurangnya penggunaan aplikasi pendukung pada \\
& materi fisika yang dipahami mahasiswa calon guru
\end{tabular}

3 Sintawati \& Indriani (2019).

Pentingnya (TPACK) Guru di Era Revolusi Industri 4.0, 417-422.

Sholihah, Yuliati, \& Wartono. (2016).

Peranan TPACK terhadap

Kemampuan Menyusun Perangkat Pembelajaran Calon Guru Fisika dalam Pembelajaran Post-Pack, 144153.

Ariyati (2018). Kemampuan PCK Calon Guru Biologi Menyusun RPP pada Praktik Microteaching.
Untuk mengintegrasikan CK, PK, dan PCK menjadi satu kesatuan yang utuh dan dapat menghasilkan proses pembelajaran yang efisien, efektif, dan menarik sudah seharusnya calon guru sebagai pendidik dimasa kini dan masa depan, tentunya harus lebih meningkatkan keterampilannya di era MEA ini, sehingga dapat bersaing dan lebih berkembang untuk menjadi pendidik yang profesional kelak.

TPACK memiliki peranan penting dan memiliki pengaruh yang kuat terhadap kemampuan menyusun perangkat pembelajaran. Komponen kemampuan menyusun RPP yang masih kurang adalah kemampuan merancang kegiatan pembelajaran. Kesalahan calon guru fisika dalam merancang kegiatan pembelajaran adalah meletakkan kegiatan apersepsi pada kegiatan inti, bukan di kegiatan pendahuluan. Hasil analisis pada kegiatan inti menunjukkan bahwa calon guru fisika masih mengalami kesulitan untuk menerapkan pendekatan saintifik (saintific approach) dalam kegiatan belajar mengajar fisika.

Mendapatkan bahwa keterampilan PCK calon guru dalam penyusunan RPP termasuk kategori baik yaitu (71, 06\%). Artinya secara umum calon guru sudah mampu menyusun RPP dengan baik. 


\begin{tabular}{|c|c|c|}
\hline No & Artikel Terkait & Uraian \\
\hline 6 & $\begin{array}{l}\text { Menggunakan TPACK: } \\
\text { Dhawati \& Hariyatmi. (2017). } \\
\text { Kemampuan TK calon guru biologi } \\
\text { FKIP UMS. SeminarPendidikan } \\
\text { Biologi dan Sains II, 649-654. }\end{array}$ & $\begin{array}{l}\text { Kelebihan: } \\
\text { untuk mengurangi terjadinya miskonsepsi dan } \\
\text { kurangnya pemahaman peserta didik mengenai konsep } \\
\text { fisika yang diajarkan, dapat menggunakan berbagai } \\
\text { software dan hardware contohnya PPT untuk } \\
\text { menampilkan materi belajar fisika, dengan } \\
\text { menyisipkan animasi dan video pembelajaran sehingga } \\
\text { pembelajaran lebih atraktif. } \\
\text { Kekurangan: } \\
\text { belum semua calon guru mampu menerapkan TPACK } \\
\text { atau menggunakan teknologi. }\end{array}$ \\
\hline 7 & $\begin{array}{l}\text { Tidak menggunakan TPACK: } \\
\text { Suciati \& Astuti (2016). Analisis } \\
\text { Rencana Pelaksanaan Pembelajaran } \\
\text { (RPP) Mahasiswa calon guru biologi. } \\
\text { Edusains,192-200. }\end{array}$ & $\begin{array}{l}\text { Kelebihan: } \\
\text { tidak memerlukan biaya untuk internet dan gadget. } \\
\text { Kelemahan: } \\
\text { calon guru kesulitan menyesuaikan antara metode } \\
\text { belajar dengan indikator pembelajaran saat memilih } \\
\text { dan menggunakan media serta variasi sumber belajar } \\
\text { sehingga lebih banyak menggunakan metode ceramah. } \\
\text { Kurangnya sarana dan prasarana sekolah untuk } \\
\text { menunjang terlaksananya pembelajaran menggunakan } \\
\text { teknologi. }\end{array}$ \\
\hline
\end{tabular}

Hasil analisis beberapa artikel terkait sebagaimana pada Tabel 1 menunjukkan bahwa dalam penyusunan RPP masih ditemukan hal-hal sebagai berikut: 1) masih terdapat beberapa kesalahan dan kekurangan, ketidak sesuaian (Chusni et al., 2017), 2) masih rendah penerapan bidang teknologi (Supriyadi et al. 2018; Dhawati \& Hariyatmi, 2017), masih ada kesulitan menerapkan pendekatan saintifik (Sholihah et al., 2016), 3) sudah berkategori baik penerapan PCK dalam penyusunan RPP (Ariati, 2018). Hal ini bermakna bahwa penerapan TPACK dalam penyusunan RPP masih perlu dioptimalkan sehingga pembelajaran lebih efisien, efektif, dan menarik bagi siswa yang mengikuti pembelajaran (Sintawati \& Indriani, 2019).

Kelebihan penggunaan TPACK yang dilakukan oleh calon guru dalam penyusunan RPP dapat dilihat dari efektif tidaknya proses pembelajaran yang telah dilakukan dan pembelajaran akan lebih menarik dengan menggunakan teknologi didalamnya. Kelemahan penerapan TPACK dalam penyusunan RPP dialami oleh calon guru yang belum terampil menggunakan teknologi yang ada (Dhawati \& Hariyatmi, 2017). Selain itu juga dipengtaruhi oleh kurangnya sarana dan prasarana yang dimiliki sekolah, sehingga dalam pelaksanaan pembelajaran masih minim dan perlu ditingkatkan lagi (Mansur, 2020). Meskipun terdapat kelebihan dalam mengembangkan RPP yang tidak menerapkan TPACK sebagaimana kajian Suciati \& Astuti (2016), namun untuk saat ini seorang guru terutama guru IPA sudah menjadi suatu keharusan untuk menyusun RPP yang menerapkan TPACK untuk meningkatkan sistem pembelajaran yang lebih baik.

Untuk mengintegrasikan teknologi informasi dan komunikasi dalam mengajar, maka calon guru diharapkan dapat menguasai keterampilan tersebut, sehingga dapat mewujudkan tujuan pendidikan nasional dan bersaing dengan bangsa lainnya di era revolusi industri 4.0 dan era MEA saat ini (Arbiyanto et al., 2018). Penerapan TPACK merupakan realisasi guru tentang memahami teknologi, serta untuk membantu siswa dalam memecahkan masalah belajar, mengembangkan konsep pengetahuan yang lebih mudah 
dipahami (Nasar, 2020).

Hasil kajian didapatkan bahwa penerapan TPACK dalam penyusunan RPP oleh guru IPA belum terealisasi secara optimal, sehingga berdampak pada kualitas pendidikan bagi siswa. Oleh karena itu, pada era teknologi dan sistem digitalisasi saat ini, mengharuskan bagi calon guru IPA untuk memulai dan melaksanakan penyusunan RPP yang didalamnya menerapkan TPACK, sehingga kualitas pendidikan dapat ditingkatkan ke arah yang lebih baik.

\section{Kesimpulan}

Berdasarkan hasil dari kajian ini dapat disimpulkan bahwa kemampuan TPACK (Technological Pedagogical and Content Knowladge) calon guru IPA dalam menyusun rencana pelaksanaan pembelajaran dapat dilihat dari kelebihan dan kekurangannya. Untuk mempresentasikan konsep yang dipelajari siswa diperlukan media yang baik agar konsep yang abstrak dapat disampaikan dengan baik dan dibayangkan dengan real. Adapun kelebihan yang dihasilkan dapat dilihat dari efektif tidaknya proses pembelajaran yang telah dilakukan dengan menggunakan teknologi didalamnya. Sedangkan kekurangannya dialami oleh guru yang belum cakap teknologi. Tentunya, kemampuan calon guru IPA dalam menyusun RPP masih perlu ditingkatkan pada beberapa aspek penerapan TPACK yang memerlukan proses untuk mendapat sumber keterampilan dan pengetahuan baru yang diperlukan bagi membentuk guru yang professional.

\section{Daftar Pustaka}

Arbiyanto, U. F., Widiyanti, \& Nurhadi, D. (2018). Kesiapan TPACK Calon Guru Bidang Teknik di Universitas Malang. Jurnal Teknik dan Pembelajaran, 1-9.

Ariyati, E. (2018). Kemampuan Pedagogical Content Knowledge Calon Guru Biologi Menyusun RPP pada Praktik Microteaching. Edukasi: Jurnal Pendidikan, 16(1), 82-92.

Chusni, M. M., Winda, S. W., Agustina, R. D., \& Malik, A. (2017). Peningkatan Kemampuan Menyusun Rencana
Pelaksanaan Pembelajaran (RPP) Berbasis Saintifik Bagi Calon Guru Fisika. Scientiae Educatia: Jurnal Pendidikan Sains, 6(2), 125-143.

Dhawati, D. A., \& Hariyatmi. (2017). Kemampuan TK Calon Guru Biologi FKIP UMS. Seminar Pendidikan Biologi dan Sains II, 649-654.

Fakhruddin, Zuhdi, M., \& Kusmayenti, Y. (2007). Pengelolaan Pembelajaran Melalui Penerapan Strategi Pembelajaran Multi Kecerdasan pada Siswa Kelas VII/ A SMPN 1 Pangkalan Kerinci. Jurnal Geliga Sains, 19-24.

Harris, J. B., Grandgenett, N., \& Hofer, M. (2012). Testing an Instrument Using Structured Interviews to Assess Experienced Teachers TPACK. Journal Teacher Education Faculty Proceedings \& Presentation, 1-15.

Innaha, R. (2018). Kemampuan Technological Pedagogical and Content Knowledge (TPACK) Guru IPA di Sekolah Inklusi SMP Negeri 23 Surakarta Tahun Ajaran 2017-2018. 1-13.

Koh, J. H. L., Chai, C. S., \& Tay, L. Y. (2014). TPACK-in-Action: Unpacking the Contextual Influences of Teachers' Construction of Technological Pedagogical Content Knowledge (TPACK). Computers \& Education, 78, 20-29.

Mulyasa, E. (2007). KurikulumTingkatsatuan Pendidikan (KTSP).Bandung: PT Remaja Rosdakarya.

Mansur, H. (2020). Evaluasi Kemampuan Guru Melaksanakan Pembelajaran K-13 Berbasis TPACK Model Countenance Evaluation. International Journal of Innovation, Creativity and Change, 1-19.

Nasar, A. (2020). Analisis Kemampuan Guru IPA Tentang Technological Pedagogical Content Knowledge pada SMP/MTs di Kota Ende. OPTIKA : Jurnal Pendidikan Fisika, 9- 20.

Nazir, M. (2003). Metode Penelitian. Yogyakarta: Pustaka Pelajar.

Rahmadi, I. F. (2019). Technological Pedagogical Content Knowledge (TPACK): Kerangka Pengetahuan Guru Abad 21. Jurnal Pendidikan Kewarganegaraan, 6(1), 65-74. DOI: 10.32493/jpkn.v6i1.y2019.p65-74 
Reski, A., \& Sari, D. (2020). Analisis Kemampuan TPACK Guru Fisika SeDistrik Merauke. Jurnal Kreatif Online, 1-8.

Rondiyah, A. (2017). Pembelajaran Sastra Melalui Bahasa dan Budaya untuk Meningkatkan Pendidikan Karakter Kebangsaan di Era MEA (Masyarakat Ekonomi Asean). 141-147.

Sholihah, M., Yuliati, L., \& Wartono. (2016). Peranan TPACK terhadap Kemampuan Menyusun Perangkat Pembelajaran Calon Guru Fisika dalam Pembelajaran Pos-Pack. Jurnal Pendidikan, 144-153.

Shulman. (1986). Pedagogical Content Knowledge: Teachers' Integration Of Subject Matter, Pedagogy, Students, And Learning Environments. NARST, 14. https://narst.org/research-matters/ pedagogical-content-knowledge

Sintawati, M., \& Indriani, F. (2019). Pentingnya Technological Pedagogical Content Knowledge (TPACK) Guru di Era Revolusi Industri 4.0. Seminar
Nasional Pagelaran Pendidikan Dasar Nasional (PPDN), 417-422.

Suciati, R., \& Astuti, Y. (2016). Analisis Rencana Pelaksanaan Pembelajaran (RPP) Mahasiswacalon Guru Biologi. Edusains, 192-200.

Supriyadi, Bahri, S., \& Waremra, R. S. (2018). Kemampuan Technological Pedagogical Content Knowladge (TPACK) Mahasiswa pada Matakuliah Strategi Belajar Mengajar Fisika. Jurnal Inspirasi Pendidikan, 8(2), 1-9. DOI: https://doi.org/10.21067/jip.v8i2.2632

Wulan, A. R. (2016). Kemampuan Calon Guru Biologi dalam Menyusun Rubrik Analitis pada Assesmen Kerja. Jurnal Pendidikan Matematika dan Sains.

Yusuf, I., Widyaningsih, S. W., \& Purwati, D. (2015). Pengembangan Perangkat Pembelajaran Fisika Modern Berbasis Media Laboratorium Virtual Berdasarkan Paradigma Pembelajaran Abad 21 Kurikulum 2013. Pancaran, 189-200. 